\title{
ON THE TRUE NATURE OF THE AZYGETHIDAE (CHILOPODA: GEOPHILOMORPHA)*
}

\author{
By R. E. Crabill, jr.
}

Smithsonian Institution, U. S. National Museum, Washington D. C.

The family Azygethidae was proposed for the reception of a single genus and species, Azygethus atopus, by R. V. Chamberlin in his I 920 study $^{1}$ of the Australian region's myriopod fauna. The new group's suprageneric rank was defended really on two grounds. The ultimate pedal segment reportedly had normal pleural sclerites, but even more remarkably this segment was said to bear a pair of spiracles. If the members of the genus did indeed all normally possess ultimate pedal segment spiracles, then their allocation to a new family would surely be justified, for they would thereby differ, not only from all other Geophilomorpha, but even from all other centipedes.

This character was so extraordinary that, sixteen years later, Attems expressed reservations as to its authenticity, and, regretting the total lack of figures, he urged that the specimen be re-examined. Nevertheless, in $1926^{2}$ he did include Azygethidae in his treatment clearly implying his suspicion that the critical character might have been misrepresented originally.

And there the matter has remained until the present. No subsequent specimens of atopus have ever been discussed. No new species have ever been referred to the family. The original types have never been re-examined. In short, no corroborative evidence has ever been adduced in support of Chamberlin's original interpretation.

Furthermore, if we were to discount, for the moment, the spiracles and pleurites of the ultimate pedal segment and then attempt to imagine to what other family and genus the species could belong, our endeavor would prove fruitless. There are so many critical errors in the original description to lead one astray, that even a man of At-

*This study was undertaken with the aid of a grant from the National Science Foundation and is published with the aid of a grant from the Museum of Comparative Zoology at Harvard College.

${ }^{1}$ The Myriopoda of the Australian Region, Bull. Mus. Comp. Zool. Harvard, 64(1): 32, (1920).

${ }^{2}$ Handbuch der Zoologie, Kukenthal and Krumbach, Bd. 4: 366, (1926). of families. Two years later he failed even to mention the name ${ }^{3}$, but

${ }^{3}$ The Myriopoda of South Africa, Ann. South African Museum, 26, (1928). in his great monograph of $1929^{4}$ he referred to the family again,

${ }^{4}$ Geophilomorpha, in Das Tierreich, Lief. 52:347, (1929). 
tems' broad experience and at times almost clairvoyant insight could not possibly have guessed to which of the existing genera and families atopus might be referrable.

Thanks to the hospitality of Dr. Herbert W. Levi, who is in charge of the Arachnida and Myriapoda at Harvard's Museum of Comparative Zoology, I have been able to study the holotype and paratype. Both are females that were collected by W. M. Mann at Levuka on Fiji. Without the slightest doubt in my mind, both are referrable to the oryid Orphnaeus brevilabiatus (Newport). which is probably the most widespread and common geophilomorph of the world's tropics.

Let us examine certain parts of the original description in light of what the type specimens themselves disclose. I shall not discuss those features that are accurately, or essentially accurately, described therein.

The mandible is said to have "a single pectinate lamella". At lower magnifications this appears superficially to be the case; however, optimal preparation and observation reveal the mandibles unquestionably to be those of an oryid; they are not geophiliform. The pectinate lamellae are simply pressed tightly against the distal end of the mandible, giving it, at first sight, a geophiliform appearance.

The "coxae", i. e. the coxosternal sides, of the first maxillae are reportedly "wholly discrete", that is, totally separated. If the reader will examine figure I, plate $\mathrm{IO}$, he will see that the coxosternum is continuous and that there is not the slightest division at point $\mathrm{E}$. The two medial processes or lobes, D, are of course discrete, as they always are. Perhaps Dr. Chamberlin confused the two in preparing his original analysis.

Ventral pores are said to be absent, but ventral pores are present and, in aggregate, form the patterns that are so distinctive of brevilabiatus.

"Last pediferous segment with coxae distinct from the pleurae. .." Precisely what Chamberlin meant here is unclear; however, his use of the world pleurae, which is plural, implies a reference to pleural sclerites rather than to lateral body wall or membrane. In fact, between the leg base and tergite there is a weakly sclerotized plate-like protuberance which appears to be an out-folding of the lateral body wall (plate IO, fig. 2, F). This same structure is to be seen in specimens of $O$. brevilabiatus; it is more pronounced in some than others. Probably it represents an abortive paratergite, a serial homologue of the more anterior, typical paratergites. In any event, the statement 
on p. 32, that "the pleural plates of the segment [are] normal" is quite misleading.

Finally, the ultimate pedal segment was reported to have a pair of spiracles, and in fact it has such spiracles (fig. 2, F). At the same time, there are mitigating circumstances. First, these spiracles occur only on the holotype: the paratype, otherwise identical with it, lacks them altogether. Secondly, the nature of the holotype's spiracles clearly suggests them to be anomalous, in this case probably ontogenetic freaks. Both are abortive, the left one more so than the right, and there is no evidence that either was ever functional. Both evidently lack a connection with the tracheal chain linking the more anterior, normal spiracles.

Such spiracular anomalies are not unknown. Indeed, I have reported having found one in a cryptopid centipede, Scolopocryptops sexspinosa (Say) ${ }^{5}$. In this case anomalous spiracles were discovered on the 7 th pedal segment, which normally lacks them, although in a related genus, Dinocryptops, the 7 th segment normally has them.

Thereby the old mystery surrounding the apocryphal family Azygethidae appears to be resolved. Azygethus atopus Chamberlin is a junior synonym of Orphnaeus brevilabiatus (Newport), and Azygethidae falls as a junior synonym of Oryidae. In closing I cannot help but wonder what other chilopod names owe their raison d'être to nothing more than to such sporadic, anomalous characters, and how long they will continue to obscure the real fabric of the system before their paroles are terminated.

${ }^{5}$ On the reappearance of a possible ancestral characteristic in a modern chilopod, Bull. Brooklyn Ent. Soc., 50(5): 133-136, (1955).

\section{Explanation of Plate 10 Azygethus atopus Chamberlin}

Figure 1. Paratype. First maxillae: left two-thirds, with adjacent second maxillae, the setae deleted. $A=$ lappet of coxosternum. $B=$ lappet of telopodite. $\mathrm{C}=$ telopodite. $\mathrm{D}=$ right medial lobe. $\mathrm{E}=$ coxosternum. $\mathrm{F}=$ hidden continuation of coxosternum concealed beneath anterior edge of second maxillary coxosternum.

Figure 2. Holotype. Posterior-most body segments: right side tilted slightly downward, setae deleted. $A=$ tergum covering the postpedal segments. $B=$ tergite of ultimate pedal segment. $C=$ Pretergite of ultimate pedal segment. $\mathrm{D}=$ Tergite of penultimate pedal segment. $\mathrm{E}=$ right ultimate leg. $F=$ Spiracle and plate-like bulge of ultimate pedal segment. $G=$ Coxopleuron. $\mathrm{H}=$ Parapretergite. $\mathrm{I}=$ Stigmopleurite of penultimate pedal segment. $\mathrm{J}=$ Paratergite of penultimate pedal segment. 

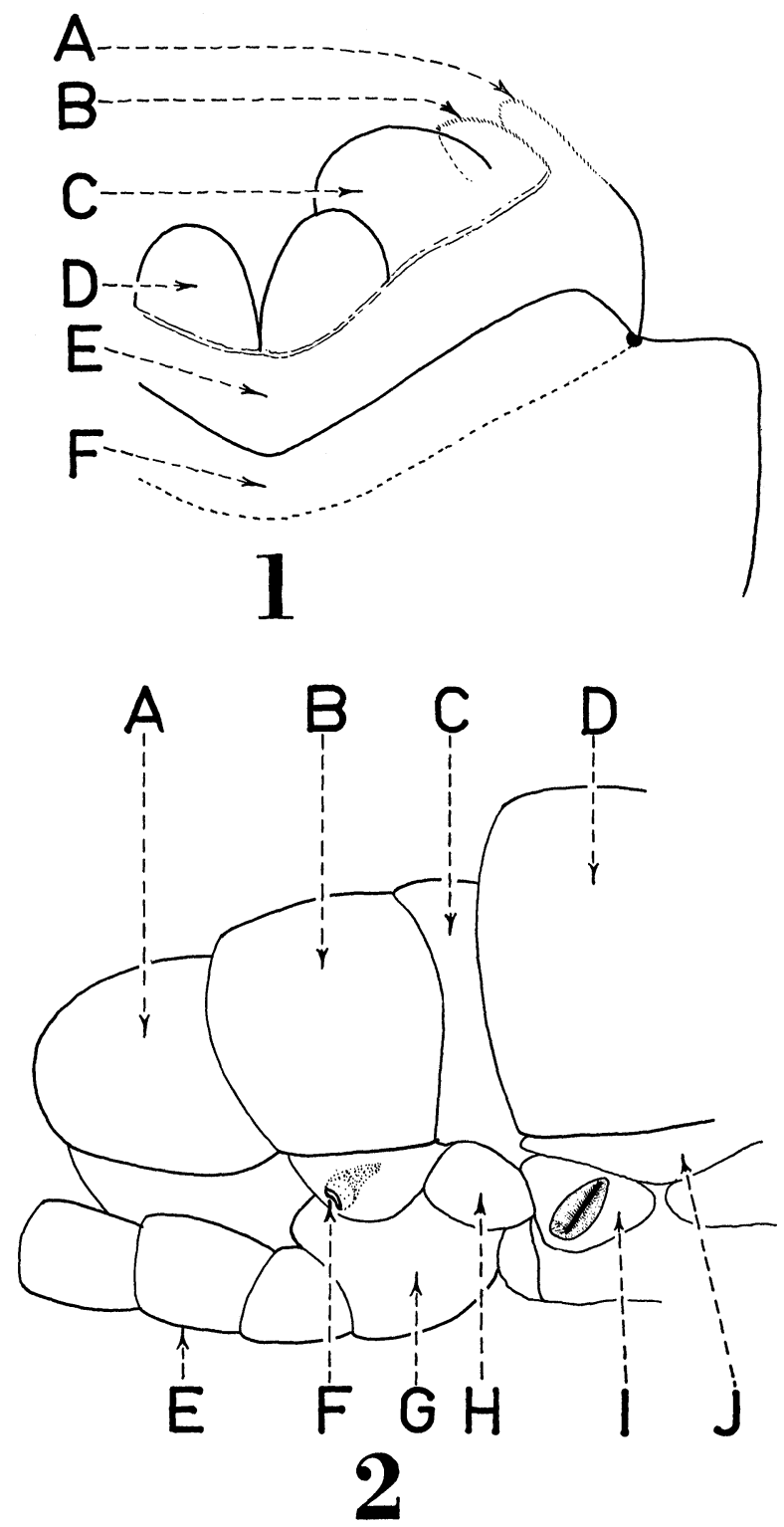

Crabill - Azygethidae 

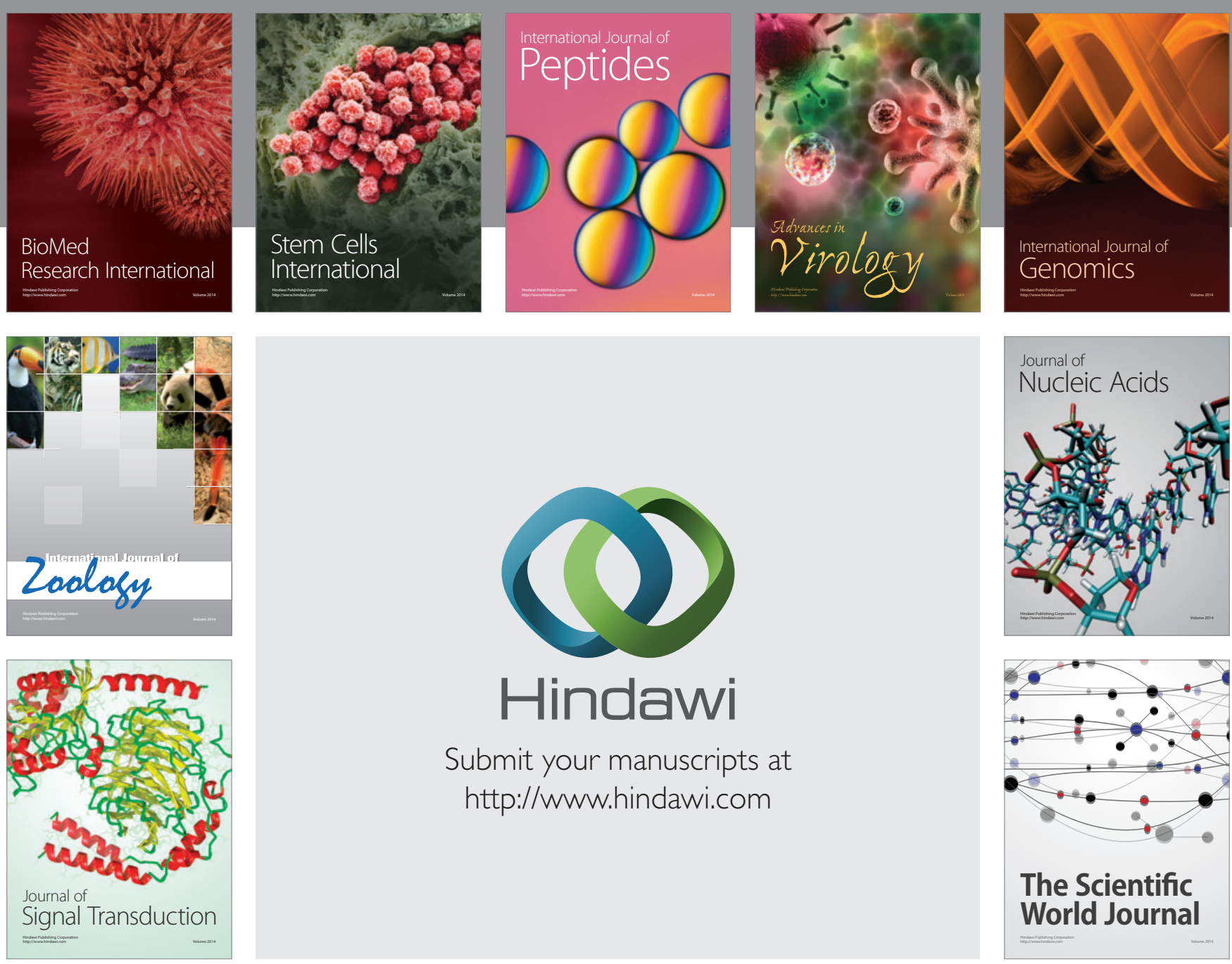

Submit your manuscripts at

http://www.hindawi.com
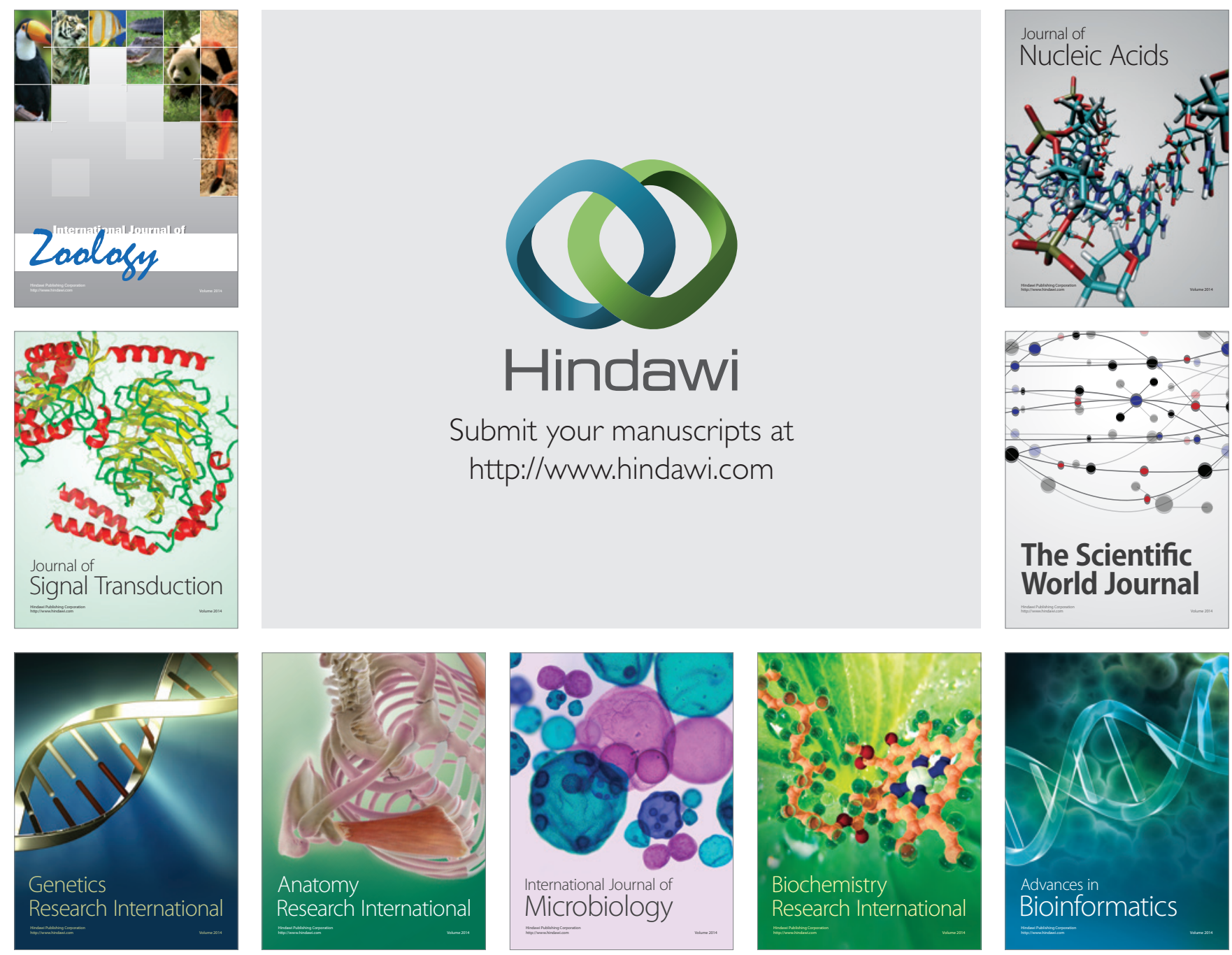

The Scientific World Journal
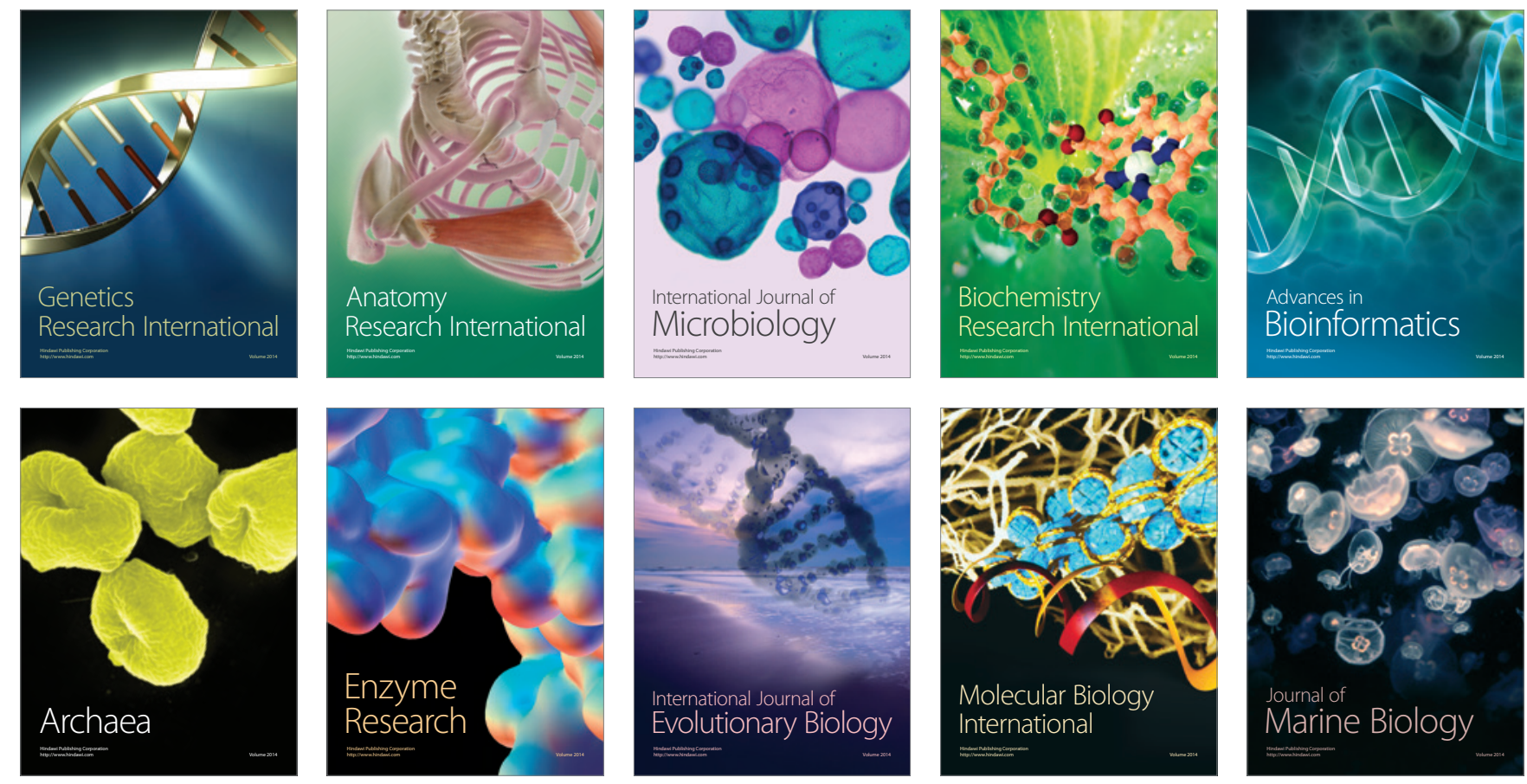